\title{
Present stage of embryo transfer and the International Embryo Transfer Society (I.E.T.S.)
}

\author{
W.W. LAMPETER \\ Institut für Tierzucht und Tierhygiene der L.M.U., \\ 8000 München 22, Federal Republic of Germany
}

The International Embryo Transfer Society (I.E.T.S.) has 560 members from 26 countries (Jan. 1982) and is serving its members with information related to E.T. This service includes abstracts, literature reviews and summaries, published in a newsletter. It holds a yearly meeting and publishes all reports presented at the meeting in "Theriogenology".

About 35000 calves were produced worldwide by E.T. techniques in 1981. Embryo collection and transfer of bovine embryos is done worldwide mostly non-surgically. The most widely used farm animal for E.T. is the cow.

\section{Cow embryo culture in vitro}

L.K. ERNST, A.K. GOLUBEV, Z.N. MAKAROVA, R.S. MAMLEEV and T.I. KUZMINA

All-Union Research Institute of Farm Animal Breeding and Genetics, Leningrad, U.S.S.R.

Fertilization of the cow oocytes matured in vitro to the metaphase II stage resulted in the cleavage of the oocytes. The percentage of cleaving oocytes averaged 13.9. In some experiments it amounted to $33.7 \mathrm{p}$. 100 . The cleaving embryos developed to the morula and aven blastocyst stage. The mechenisms of the cleavage of cow oocytes are discussed.

\section{Immuno- and cytogenetic methods and distant hybridization in improvement of animals}

\author{
V.N. TIKHONOV \\ Institute of Cytology and Genetics, Academy of Sciences of the U.S.S.R., \\ Siberian Division, Novosibirsk, U.S.S.R.
}

The new forms of commercial $L W H$ (Landrace $\times$ Wild Boar Hybrid) are the result of hybridization between Swedish Landrace and European, Middle Asian and Far East wild boars. They have good meat features and a high resistance to unfavourable conditions of industrial pig breeding. About $3000 L W H$ of $F_{1}-F_{8}$ were studied by immuno- and cytogenetic methods. A wide range of antigens and 5 identified chromosomes were used as genetic markers. The $L W H$ homoand heterozygous for translocations $15 / 17$ and $16 / 17(2 n=36$ and 37) with high viability and fertility were produced. 